\title{
PENINGKATAN MOTIVASI DAN HASIL BELAJAR SISWA MELALUI PENERAPAN MODEL PEMBELAJARAN Siklus Belajar 5E (Learning Cycle 5E) PADA KONSEP SISTEM EKSKRESI
}

\author{
Nenen Shanti W $*^{1}$, Ukit $^{2}$ \\ MAN 2 Kota Bandung; Jl. Desa Cipadung No.57 Tlp. 022) 7811725 Kel. Cibiru Kota \\ Bandung 40615; \\ Program Studi Pendidikan Bioogi, Program Sarjana S1, Universitas Islam Negeri Sunan \\ Gunung Djati Bandung; Jl. A.H. nasution No. 105 Cibiru- bandung 40614 /Tlp. 022-7802276 \\ Fax. 022-7802276/ www.ftkuinsgd.ac.id
}

nenenshantiwijayanti@yahoo.com; ukit21@uinsgd.ac.id

\begin{abstract}
Abstrak. Tujuan penelitian ini adalah mengetahui peningkatan motivasi dan hasil belajar siswa kelas Lintas Minat (kelas IIS-1, IIS-2, dan IIS-3) pada pelajaran Biologi kompetensi dasar Sistem Ekskresi menggunakan model pembelajaran Siklus Belajar 5E (learning cycle 5E) di MAN 2 Kota Bandung. Metode yang digunakan dalam penelitian ini adalah penelitian tindakan kelas (PTK). Setiap siklus dilakukan 2 kali pertemuan. Teknik pengumpulan datanya menggunakan observasi dan tes. Adapun teknik analisis datanya menempuh deskripsi kegiatan pembelajaran guru dan siswa selama tindakan menggunakan model pembelajaran Siklus Belajar 5E (learning cycle 5E), kemudian dihitung jumlah dan rata-rata, serta untuk hasil belajar dihitung jumlah siswa tuntas dan tidak tuntas berikut persentasenya. Dari hasil diperoleh bahwa penggunaan model pembelajaran 5E (learning cycle 5E) dapat meningkatkan motivasi belajar siswa kelas Lintas Minat (kelas IIS1, IIS-2, dan IIS-3) pada pelajaran Biologi kompetensi dasar Sistem Ekskresi di MAN 2 Kota Bandung. dibuktikan dengan meningkatnya motivasi belajar siswa setelah tindakan (siklus I dan siklus II). Tingginya motivasi belajar tersebut disertai dengan meningkatnya hasil belajar siswa setelah tindakan dimana diperoleh rata-rata nilai 81,61, siswa tuntas sebanyak 42 siswa $(95,45 \%)$, dan siswa tidak tuntas sebanyak 2 siswa $(4,55 \%)$ dan hasil belajar siswa pada prasiklus sebesar rata-rata 70,58, siswa yang tuntas 13 siswa $(34,21 \%)$, siklus ke-1 rata-rata hasil belajar 77,45 , siswa tuntas sebanyak 30 siswa $(78,95 \%)$ dan meningkat agi pada siklus ke-2 dengan rata-rata 85,34 , siswa yang tuntas mencapai KKM sebanyak 35 siswa $(92,11 \%)$
\end{abstract}

Kata Kunci: Motivasi, Prestasi Belajar, Biologi-sistem ekskresi, Model 5E (learning cycle 5E)

The purpose of this research is to know the improvement of motivation and learning outcome of the students of Cross-Interest Class (IIS-1, IIS-2, and IIS-3) in Biology lesson of Basic Competence of Excretory System using Learning Cycle 5E Model in MAN 2 Bandung. The method used in this research was classroom action research (PTK). Each cycle was done in 2 times meeting. Data collection techniques used ware observation and tests. The data analysis technique takes the description of teacher and student learning activities during the action using learning cycle 5E model, then calculated the number and average, and for the learning outcome was calculated by the total number of complete and unfinished students and the percentage. From the results obtained that the use of learning cycle $5 E$ model can improve the motivation of learning class of Cross-Interests (IIS-1, IIS-2, and IIS-3) in Biology lessons of basic competence of Excretory System in MAN 2 Bandung. It was evidenced by the 
increase of student learning motivation after action (cycle I and cycle II). The high learning motivation was accompanied by the increase of students' learning outcomes after the action where the average score of 81.61, 42 students (95.45\%) and the student learning outcome before the cycle was on average of 70.58 with 13 students (34.21\%), 1st cycle average learning outcomes was 77.45 with 30 students (78.95\%) and increased in the second cycle with an average of 85.34 with 35 students (92.11\%)

Keywords: Motivation, Learning Achievement, Biology-excretion system, learning cycle $5 E$

\section{PENDAHULUAN}

Motivasi sangat penting dalam kegiatan belajar, sebab adanya motivasi mendorong semangat belajar dan sebaliknya kurang adanya motivasi akan melemahkan semangat belajar. Hal ini sebagaimana pendapat Sardiman (2001: 73) bahwa dalam proses pembelajaran, motivasi merupakan keseluruhan daya penggerak di dalam diri siswa yang memberikan kegiatan belajar sehingga tujuan yang dikehendaki oleh subjek belajar tersebut tercapai. Indikasi siswa memiliki motivasi yang tinggi dalam belajar adalah ulet, berkonsentrasi tinggi, kritis, serta tekun dalam mengerjakan tugas. Dengan motivasi belajar yang tinggi, maka prestasi belajarpun akan meningkat.

Namun demikian, dalam pembelajaran Biologi Kompetensi Dasar system ekskresi pada siswa kelas XI Lintas minat (dari kelas IIS-1, IIS-2, dan IIS-3), MAN 2 Kota Bandung, motivasi belajarnya sangat rendah. Terlihat dari indikator sebagai berikut: Pertama, sebagian besar siswa masih terlihat kurang serius dalam mengerjakan tugas dan terkesan asal-asalan, mungkin karena kelas ini merupakan kelas lintas minat, dimana siswa dari kelas IIS-1, IIS-2, dan IIS-3 secara sengaja menuju kelas lintas minat dari kelas masing-masing, sehingga banyak siswa yang terkesan enggan untuk belajar,, bahkan tidak jarang yang menyontek pekerjaan temannya saat ujian. Ketekunan dan keuletan dalam belajar atau mengerjakan tugas sangatlah penting dalam belajar sebagai indikator motivasi. Sebagaimana menurut Sardiman (2001) bahwa, "tekun sangat penting dalam belajar karena menandakan sikap bersungguh-sungguh dalam belajar sehingga dapat meraih prestasi yang baik."

Kedua, rendahnya partisipasi siswa dalam belajar seperti bertanya dan mengemukakan pendapat. Hanya 2-3 siswa $(7,89 \%)$ yang aktif berpartisipasi dalam belajar baik bertanya maupun mengemukakan pendapat apabila guru memberikan kesempatan kepada siswa untuk kedua hal aktivitas tersebut. partisipasi bertanya dan berpendapat sangatlah penting dalam belajar serta menandakan motivasi belajar yang tinggi, sebagaimana menurut Rusyan, dkk. (1989: 123) bahwa "motivasi erat kaitannya dengan aktivitas belajar, karena salah satu fungsi motivasi adalah mengarahkan aktivitas belajar siswa."

Ketiga, rendahnya konsentrasi siswa pada saat menyimak penjelasan guru, dimana masih terdapat siswa yang mengobrol dengan siswa yang lain dan mengantuk. Konsentrasi dalam belajar sangatlah penting, sebagaimana pendapat Nuraini (2011) disebutkan bahwa, "konsentrasi adalah proses memusatkan segenap kekuatan perhatian pada suatu situasi belajar. Di dalam konsentrasi ini keterlibatan mental secara detail sangat diperlukan, sehingga tidak perhatian sekedarnya."

Keempat, hasil belajar Biologi kompetensi dasar system ekskresi pada siswa kelas XI Lintas Minat (dari kelas IIS-1, IIS-2, dan IIS-3), terdapat 25 siswa $(65,79 \%)$ yang harus remedial karena nilainya di bawah Kriteria Ketuntasan Minimal (KKM) atau di bawah nilai 76 dengan rata-rata nilai 70,58 yang sekaligus 
menandakan hasil belajar siswa yang rendah. Motivasi sangat erat kaitannya dengan hasil belajar. Apabila motivasi belajar tinggi maka prestasi belajarpun akan meningkat, begitupun sebaliknya. Sebagaimana pendapat Dimyati dan Mudjiono (2002) menyatakan bahwa, motivasi belajar pada siswa sangat berpengaruh pada hasil belajar. Lemahnya motivasi atau tidak adanya motivasi belajar akan melemahkan kegiatan belajar, sehingga mutu hasil belajar akan menjadi rendah.

Permasalahan rendahnya motivasi dan hasil belajar siswa kelas XI Lintas Minat (dari kelas IIS-1, IIS-2, dan IIS-3) MAN 2 Kota Bandung tersebut harus segera dipecahkan. Oleh karena itu, penciptaan kondisi pembelajaran yang menyenangkan dan mampu memotivasi siswa merupakan tugas dan tanggungjawab guru. Hal ini sebagaimana ditegaskan dalam Peraturan Pemerintah Nomor 19 Tahun 2005 tentang Standar Nasional Pendidikan Bab IV Pasal 19 Ayat (1) yang secara garis besarnya bahwa proses pembelajaran diselenggarakan secara interaktif, menyenangkan serta mampu memotivasi siswa untuk kreatif dan mandiri.

Untuk menciptakan suasana pembelajaran sebagaimana disebutkan di atas, pemilihan model pembelajaran yang tepat sangat diperlukan. Sudrajat (2008) mengemukakan bahwa model pembelajaran pada dasarnya merupakan bentuk pembelajaran yang tergambar dari awal sampai akhir yang disajikan secara khas oleh guru. Dengan kata lain, model pembelajaran merupakan bungkus atau bingkai dari penerapan suatu pendekatan, metode, dan teknik pembelajaran. Oleh karena itu, guru dituntut mampu menerapkan model pembelajaran yang tepat dalam upaya memotivasi siswa dalam belajar sehingga mampu mencapai tujuan pembelajaran yang telah ditetapkan.

Hasil wawancara pendahuluan, ternyata siswa yang memilih kelas lintas minat dari IPS ke Biologi, adalah karena mereka mulai jenuh denan pembelajaran IPS yang rata-rata hanya bersifat hapalan dan teoritis peritungan. Sedangkan di Biologi mereka berharap bahwa pembelajaran akan belangsung dengan cara eksperimental, demonstrasi, dan lainnya, sehingga mampu memahami konsepkonsep biologi dengan cara langsung.

Model pembelajaran learning cycle $5 \mathrm{E}$ yang berorientasi pada pembelajaran kontruktivisme (constructivist approach) ini sangat memperhatikan pengalaman dan pengetahuan awal siswa serta bertujuan meningkatkan pemahaman konsep siswa. Oleh karena itu, pada setiap fase-fase pembelajaran guru dituntut untuk menciptakan kondisi pembelajaran yang beranjak dari isu-isu sains yang relevan dengan lingkungan siswa, memicu proses disequilibrium-equilibrium (ketidakseimbangan-seimbang) pada diri siswa serta memberi kesempatan kepada siswa untuk berinteraksi dengan orang lain agar siswa dapat membangun pengetahuannya secara utuh (Mabsuthoh, 2010).

Dari pengertian tersebut, model pembelajaran learning cycle $5 \mathrm{E}$ memiliki keunggulan-keunggulan. Pertama, melatih siswa lebih kritis dalam menganalisa gambar atau video terkait konsep system ekskresi. Kedua, siswa mengetahui dan mampu mengkonstruksi pengetahuannya dari hasil pengamatan, diskusi, dan berbagai aktifitas dalam pembelajaran.

Berbagai rencana sintaks dalam pembelajaran terseut, akan dibingkai dalam sebuah penelitian tindakan kelas (PTK), agar berbagai kekuragan yang sudah nambak maupun belum Nampak dalam pembelajaran akan mampu diatasi baik oleh peneliti maupun observer dalam proses refleksi dan aksi.

\section{METODE PENELITIAN}

Metode penelitian ini adalah penelitian tindakan kelas (PTK). Dalam penelitian ini penulis memilih metode PTK 


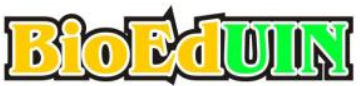

Jurnal Program Studi Pendidikan Biologi

karena diharapkan dapat dimanfaatkan untuk memperbaiki pembelajaran dikelola di kelas, serta mendapat kesempatan untuk berperan aktif dalam mengembangkan pengetahuan dan keterampilan sendiri.

Penelitian tindakan kelas dilaksanakan dalam bentuk siklus yang terdiri atas empat tahap, yakni perencanaan, pelaksanaan tindakan, observasi, dan refleksi. Tindakan penelitian ini dilakukan dua siklus sebab setelah dilakukan refleksi yang meliputi analisis dan penilaian terhadap proses tindakan sebelumnya, akan muncul permasalahan atau pemikiran baru sehingga perlu dilakukan perencanaan ulang, tindakan ulang, dan refleksi ulang.

Wardani dan Wihardit (2008: 14), berpendapat bahwa penelitian tindakan kelas (PTK) adalah penelitian yang dilakukan oleh guru di dalam kelasnya sendiri melalui refleksi diri, dengan tujuan untuk memperbaiki kinerjanya sebagai guru sehingga hasil belajar siswa menjadi meningkat. PTK adalah bentuk proses pengkajian berdaur (siklus) yang terdiri dari empat tahap yaitu (1) perencanaan (planning), (2) tindakan (action), (3) pengamatan (Observation), (4) refleksi (reflection).

\section{HASIL DAN PEMBAHASAN}

Penelitian ini dilaksanakan sebanyak dua siklus (tindakan siklus I dan Siklus II). Oleh karena itu, deskripsinyapun menyangkut kedua siklus tersebut dengan ciri utama PTK yakni: perencanaan, pelaksanaan, pengamatan, dan refleksi.

Dari hasil penelitian dapat dibahas bahwa pada aspek perencanaan tindakan siklus I dan tindakan siklus II, telah disusun rencana berupa RPP dan penyiapan alat pembelajaran berupa penyiapan alat dan bahan, serta perangkat LKS, harus operasional, karena kelas yang dijadikan objek penelitian tindakan adalah kelas IPS yang cenderung kaku dalam melaksanalkan eksperimen biologi. Hal
p-ISSN : 2338-7173

e-ISSN : 2615-0417

(Februari), Vol. (8), No.(1)

tersebut menunjukkan sangat pentingnya melakukan perencanaan yang matang. Pentingnya perencanaan pembelajaran dikemukakan Ibrahim (1993) bahwa secara garis besar perencanaan pembelajaran mencakup kegiatan merumuskan tujuan apa yang akan dicapai oleh suatu kegiatan pembelajaran, cara apa yang dipakai untuk menilai pencapaian tujuan tersebut, materibahan apa yang akan disampaikan, bagaimana cara menyampaikannya, serta alat atau media apa yang diperlukan. Dengan perencanaan pembelajaran, guru dapat memperkirakan, mempersiapkan, dan menentukan tindakan apa yang akan dilakukan pada waktu proses pembelajaran berlangsung. Pada tahap ini guru mempersiapkan segala sesuatunya agar proses pembelajaran dapat berjalan secara efektif.

Selanjutnya pada pelaksanaan proses pembelajaran diperoleh hasil pada tindakan siklus I dari kegiatan awal, inti, dan akhir pembelajaran yang berjumlah 13 indikator diperoleh rata-rata 78,08. Angka ini berada pada kategori cukup baik. Dengan demikian kegiatan guru dalam pembelajaran Biologi Kompetensi Dasar Sistem Ekskresi menggunakan model pembelajaran 5 learning sycle $(5 E)$ di kelas XI Lintas Minat (dari kelas IIS-1, IIS-2, dan IIS-3) MAN 2 Kota Bandung, cukup baik. Meningkat pada tindakan siklus II dengan diperoleh rata-rata 86,54 dengan kategori baik.

Berdasarkan hasil tersebut, proses pembelajaran yang dilakukan menggunakan model pembelajaran 5 learning sycle $(5 E)$ telah berhasil menciptakan pembelajaran yang mengharuskan siswa aktif dan kritis sehingga menggambarkan tingginya motivasi belajar siswa. Pentingnya pembelajaran yang mampu menciptakan siswa aktif dan kritis, ditegaskan pula dalam Permendiknas Nomor 41 Tahun 2007 tentang Standar Proses untuk Satuan Pendidikan bahwa pelaksanaan pembelajaran harus dilakukan secara 
interaktif serta menantang motivasi siswa untuk berpartisipasi aktif.

\section{Pembahasan Motivasi Belajar Siswa}

Dari hasil penelitian diperoleh terjadi peningkatan motivasi belajar siswa dari tindakan siklus I ke tindakan siklus II. Dari kesepuluh indikator motivasi belajar siswa diperoleh rata-rata 74. Angka ini berada pada kategori cukup tinggi. Meningkat pada tindakan siklus II dengan diperoleh rata-rata 84,5 dengan kategori motivasi tinggi. Artinya terjadi peningkatan motivasi belajar sebesar 10,5 angka dari tindakan siklus I ke tindakan siklus

II.

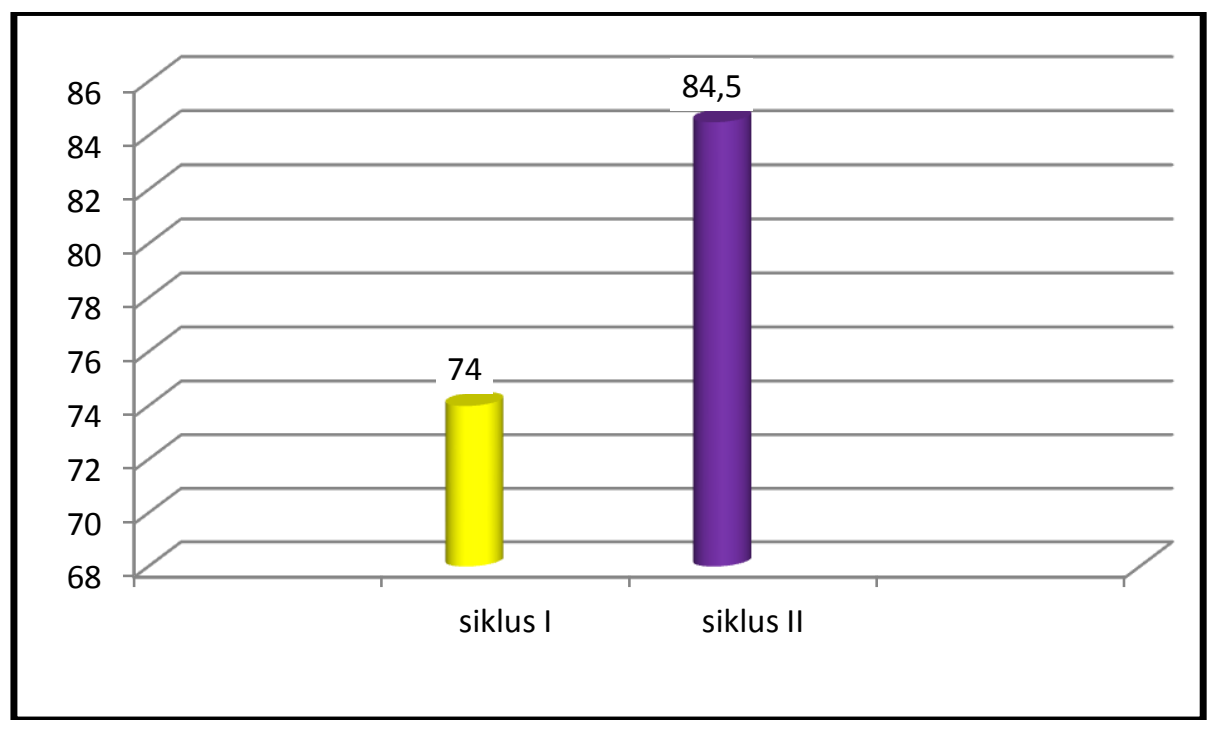

Gambar 1. Tingkat motovasi belajar siswa

Berdasarkan gambaran pelaksanaan pembelajaran menggunakan model pembelajaran 5 learning sycle $(5 E)$ yang dilakukan, telah sejalan sebagaimana dalam Permendiknas Nomor 41 Tahun 2007, bahwa pembelajaran yang dilakukan guru harus menyenangkan, dan menjadikan siswa berpikir kritis serta aktif dan mampu memotivasi belajar siswa. Yakni mampu meningkatkan motivasi belajar siswa kelas XI Lintas Minat (dari kelas IIS-1, IIS-2, dan IIS-3) MAN 2 Kota Bandung pada pembelajaran Biologi Kompetensi Dasar
Sistem Ekskresi menggunakan model pembelajaran 5 learning sycle $(5 E)$ di kelas XI Lintas Minat (dari kelas IIS-1, IIS-2, dan IIS-3) MAN 2 Kota Bandung.

\section{Pembahasan Hasil Belajar siswa}

Dari hasil penelitian diperoleh hasil belajar siswa setelah tindakan (siklus I dan siklus II) dibandingkan dengan sebelum tindakan (pra siklus) telah mengalami peningkatan. Untuk mempermudah membahasnya, disajikan dalam tabel berikut:

Tabel 1 Perbandingan hasil Belajar Prasiklus, Siklus I, dan Siklus II

\begin{tabular}{|c|c|c|c|c|c|}
\hline No & $\begin{array}{l}\text { Hal Hasil } \\
\text { Belajar }\end{array}$ & $\begin{array}{l}\text { Pra } \\
\text { Siklus }\end{array}$ & Siklus I & Siklus II & Keterangan \\
\hline 1 & Rata-rata Nilai & 70,58 & 77,45 & 85,34 & $\begin{array}{c}\text { Meningkat } 14,58 \text { angka } \\
\text { dari prasiklus dan ke } \\
\text { setelah tindakan }\end{array}$ \\
\hline 2 & $\begin{array}{l}\text { Jumlah Siswa } \\
\text { Tuntas }(\%)\end{array}$ & $\begin{array}{l}13 \text { siswa } \\
(34,21 \%)\end{array}$ & $\begin{array}{l}30 \text { siswa } \\
(78,95 \%)\end{array}$ & $\begin{array}{l}35 \text { siswa } \\
(92,11 \%)\end{array}$ & $\begin{array}{c}\text { Meningkat } 22 \text { siswa } \\
(57,9 \%) \\
\text { Dari prasiklus ke setelah }\end{array}$ \\
\hline
\end{tabular}




\begin{tabular}{|c|c|c|c|c|c|}
\hline No & $\begin{array}{c}\text { Hal Hasil } \\
\text { Belajar }\end{array}$ & $\begin{array}{c}\text { Pra } \\
\text { Siklus }\end{array}$ & Siklus I & Siklus II & Keterangan \\
\hline & & & & & tindakan \\
\hline 3 & $\begin{array}{l}\text { Jumlah Siswa } \\
\text { Belum Tuntas } \\
(\%)\end{array}$ & $\begin{array}{l}25 \text { siswa } \\
(65,79 \%)\end{array}$ & $\begin{array}{c}8 \text { Siswa } \\
(21,05 \%)\end{array}$ & $\begin{array}{c}3 \text { siswa } \\
(7,89 \%) .\end{array}$ & $\begin{array}{l}\text { Terjadi penurunan jumlah } \\
\text { siswa tidak tuntas sebanyak } \\
25 \text { siswa }(57,9 \%) \text { dari pra } \\
\text { siklus ke setelah tindakan }\end{array}$ \\
\hline
\end{tabular}

Dari tabel dan gambar di atas, dapat ditafsirkan bahwa terjadi peningkatan hasil belajar siswa pada pelajaran Sosiologi Kompetensi Dasar system ekskresi di kelas XI Lintas Minat (dari kelas IIS-1, IIS-2, dan IIS-3) MAN 2 Kota Bandung. Sebelum tindakan diperoleh rata-rata nilai 70,58 , dan setelah tindakan siklus I 77,45 serta setelah tindakan siklus II 85,34. Dengan demikian dari rata-rata nilai terjadi peningkatan 14,76 angka dari sebelum tindakan ke setelah tindakan.

Jumlah siswa yang tuntas sebelum tindakan adalah 25 siswa $(65,79 \%)$, meningkat menjadi 30 siswa $(78,95 \%)$ pada tindakan siklus I, dan meningkat lagi menjadi 35 siswa $(92,11 \%)$ pada tindakan siklus II. Artinya telah terjadi peningkatan jumlah siswa tuntas dari sebelum tindakan ke setelah tindakan sebanyak 24 siswa $(63,16 \%)$.

Jumlah siswa yang tidak tuntas sebelum tindakan adalah 25 siswa $(65,79 \%)$, menurun pada tidakan siklus I menjadi 8 siswa $(21.05 \%)$, dan menurun kembali pada tindakan siklus II menjadi 3 siswa $(7,89 \%)$. Artinya terjadi penurunan jumlah siswa yang tidak tuntas sebanyak 17 siswa dari sebelum tindakan ke setelah tindakan.

Peningkatan hasil belajar siswa pada pelajaran Biologi Kompetensi Dasar system ekskresi di kelas XI Lintas Minat (dari kelas IIS-1, IIS-2, dan IIS-3) MAN 2 Kota Bandung merupakan dampak dari meningkatnya motivasi belajar siswa. Serta tingginya motivasi belajar siswa merupakan dampak dari optimalnya pembelajaran yang dilakukan menggunakan model pembelajaran 5 Learn. Sebagaing syle (5E). sebagaimana mana pendapat (Mabsuthoh, 2010) bahwa model pembeljaran 5E berorientasi pada pembelajaran kontruktivisme (constructivist approach) ini sangat memperhatikan pengalaman dan pengetahuan awal siswa serta bertujuan meningkatkan pemahaman konsep siswa. Oleh karena itu, pada setiap fase-fase pembelajaran guru dituntut untuk menciptakan kondisi pembelajaran yang beranjak dari isu-isu sains yang relevan dengan lingkungan siswa, memicu proses disequilibrium-equilibrium (ketidakseimbangan-seimbang) pada diri siswa serta memberi kesempatan kepada siswa untuk berinteraksi dengan orang lain agar siswa dapat membangun pengetahuannya secara utuh.

Berdasarkan data hasil dan pembahasan penelitian itu, maka dapat dijawab hipotesis tindakan penelitian ini bahwa penggunaan model pembelajaran 5 Learning Sycle (5E) terbukti dapat meningkatkan motivasi dan hasil belajar siswa kelas kelas XI Lintas Minat (dari kelas IIS-1, IIS-2, dan IIS-3) pada pelajaran Biologi kompetensi dasar Sistem Ekskresi di MAN 2 Kota Bandung.

\section{DAFTAR PUSTAKA}

A.M. Sardiman. (2000). Interaksi dan motivasi Belajar Mengajar. Jakarta :PT. RajaGrafindo Persada

Arikunto, Suharsimi. (2006). Dasar-dasar Evaluasi Pendidikan. Jakarta : PT. Bumi Aksara.

Balci, S., Cakiroglus, J., \& Tekkayas, C. 2006. Engagement, exploration, 
explanation, extension, and evaluation (5E) learning cycle and conceptual change text as learning tools. Biochemistry and Molecular Biology Education. 34(3). 199-203.

Tersedia di www.sciencedirect.com.

Budprom, W., Suksringam, P., \& Singsriwo, A. 2010. Effects of learning environmental education using 5E-learning cycle with multiple intelligences and teacher's handbook approaches on learning achievement, basic science process skills and critical thinking of grade 9 students. Pakistan Journal of Social Sciences. 7(3). 200-204. Tersedia di http://docsdrive.com/pdfs.

Bybee, R. W., Taylor, J. A., Gardner, A., Scotter, P. V., Powell, J. C., Westbrook, A., \& Landes, N. 2006. The BSCS 5E instructional model: Origins and effectiveness. Laporan. Disiapkan untuk Office of Science Education National Institutes of Health. Tersedia di http://www.bscs.org/sites/ default/files/BSCS_5E_Instructiona 1_Model-Full_Report.pdf.

Danial, Endang dan Nanan Warsiah. (2009). Metode Penulisan Karya Ilmiah. Bandung: Laboratorium PKn Universitas Pendidikan Indonesia.

Dahar. R. W. 1996. Teori-teori belajar. Jakarta: Erlangga.

Dimyati dan Mudjiono. 2002. Belajar dan Pembelajaran. Jakarta: Rineka Cipta.

Effendy, Onong Uchjana. (1993). Ilmu, Teori, \& Filsafat Komunikasi. Bandung : PT Citra Aditya Bakti.

Elida Prayitno. 1989. Motivasi Dalam Belajar. Jakarta: Depdikbud

Ergin, I. 2012. Constructivist approach based 5E model and usability instructional physics. Journal Physics Education. 6(1). 14-20. Tersedia di http://www. lajpe.org.
Ergin, I., Kanli, U., \& Ünsal, Y. 2008. An example for the effect of $5 \mathrm{E}$ model on the academic success and attitude levels of students': "Inclined projectile motion". Journal of Turkish Science Education. 5(3). 47-59. Tersedia di http://www.tused.org.

Fajaroh, F. \& Dasna, I W. 2007. Pembelajaran dengan model siklus belajar (learning cycle). Artikel. Jurusan Kimia FMIPA UM. Tersedia di http://lubisgrafura.wordpress.com/2 007/09/20/pembelajaran-denganmodel-siklus-belajar-learningcycle/.

Hagerman, C. L. 2012. Effects of the 5E learning cycle on student content comprehension and scientific literacy. A Professional Paper (tidak diterbitkan). Montana State University.

Haribhai, T. S. \& Dhirenkumar, G. P. 2012. Effectiveness of constructivist 5 ' $\mathrm{E}$ ' model. Research Expo International Multidisciplinary Research Journal. 2(2). 76-82. Tersedia di www. researchjournals.in.

Hadi, Sutrisno, (1994), Metodologi Research, Yogyakarta: Yayasan Penerbitan Fakultas Psikologi UGM.

Isfan Lauhani, (t.t.), model pembelajaran example non example telah mampu meningkatkan hasil belajar siswa. Diakses melalui google search Juli 2013.

Kazu, I. Y. \& Bosu, E. 2012. Turkish vocational school students' perception of $5 \mathrm{E}$ teaching model. International Journal of Learning and Development. 2(6). 221-237. Tersedia di www.macrothink.org/ijld.

Komalasari, Kokom.
Pembelajaran
Bandung. PT. Refika Aditama


Liu, T., Peng, H., Wu, W., \& Lin, M. 2009. The effects of mobile naturalscience learning based on the $5 \mathrm{E}$ learning cycle: A case study. Educational Technology and Society. 12(4). 344-358. Tersedia di https://www.iste.org.

Mabsuthoh, N. 2010. Pengaruh model pembelajaran learning cycle terhadap hasil belajar fisika pada konsep masa jenis. Skripsi (tidak diterbitkan). Universitas Islam Negeri Syarif Hidayatullah.

Marlinang Sitompul, (2012), Penerapan model example non example mampu meningkatkan aktivitas belajar dan hasil belajar siswa, http://digilib.unimed.ac.id/UNIME D-Undergraduate-0213154/24946, Diakses Juli 2013.

Moleong, J. Lexy. (2007). Metodologi Penelitian Kualitatif. Bandung. PT Remaja Rosdakarya

Ngalim Purwanto. (2004). Psikologi Pendidikan. Bandung : PT Remaja Rosdakarya.

Nasution, S. (2009). Metode Research (Penelitian Ilmiah). Jakarta: Bumi Aksara.

Nawawi, Hadari, (1995), Metode Penelitian Bidang Sosial. Cetakan 7. Yogyakarta: Gajah Mada University Press.

Hamalik, Oemar. (2002). Proses Belajar Mengajar. Jakarta: Bumi Aksara.

Qarareh, A. Q. 2012. The effect of using the learning cycle method in teaching science on the educational achievement of the sixth graders. Journal Education Sciences. 4(2). 123-132.

Tersedia di http://www.krepu blishers.com.

Ramadhani, N. 2012. Pengaruh model pembelajaran kontruktivis $5 \mathrm{E}$ terhadap hasil belajar di SMA Laksamana Martadinata. Jurnal Pendidikan Fisika. 1(1). 45-50.

Soomro, A. Q., Qaisrani, M. N., \& Uqaili, M. A. 2011. Measuring students' attitudes towards learning physics:
Experimental research. Australian Journal of Basic and Applied Sciences. 5(11). 2282-2288. Tersedia di http://www.ajbasweb.com/ajbas.

Suastra, I W. 2002. Strategi belajar mengajar sains. Buku ajar (Tidak diterbitkan). Jurusan Pendidikan Fisika, IKIP Negeri Singaraja.

Suastra, I W. 2009. Pembelajaran sains terkini: Mendekatkan siswa dengan lingkungan alamiah dan sosial budayanya. Singaraja: Universitas Pendidikan Ganesha.

Santoso, Ras Eko Budi, (2009), ModelModel Pembelajaran, [Oline] Tresedia:

http://wyw1d.wordpress.com/2009/ 11/10/model-pembelajaranexamplenonexample/. Diakses 2 Oktober 2012.

Somantri, Muhammad Numan. (2001). Menggagas Pembaharuan Pendidikan IPS. Bandung: PT Remaja Rosda Karya.

Subana. (2009). Statistika Pendidikan. Bandung: CV. Pustaka Setia.

Sudrajat, Akhmad, (2008), Pendekatan Strategi Metode Teknik dan Model Pembelajaran. [online]: Tersedia: http://akhmadsudrajat.wordpress.co $\underline{\mathrm{m} / 2008 / 09 / 12 / \text { pendekatan-strategi- }}$ metode-teknik-dan-modelpembelajaran. Diakses 2 Oktober 2011.

Sugiyono. (2010). Metode Penelitian Kuantitatif Kualitatif dan $R \& B$. Bandung: Alfabeta.

Suparman. (ed.). (1997). Model-Model Pembelajaran Interaktif. Jakarta: STIA LAN Press.

Suryabrata, Sumadi. (1995). Psikologi Pendidikan. Jakarta : Rajawali

Sutadipura Balnadi. (1983). Aneka Problematika Keguruan. Bandung: Aneka Ilmu.

Temel, S., Yilmaz, H., \& Ozgur, S. D. 2013. Use of the learning cycle model in the teaching of chemical bonding and an investigation of 
diverse variables in prediction of achievement. International Journal of Education and Research. 1(5). 114. Tersedia di www.ijern.com.

Trianto. 2012. Model pembelajaran terpadu. Jakarta: Bumi Aksara.

Tuna, A. \& Kacar, A. 2013. The effect of $5 \mathrm{E}$ learning cycle model in teaching trigonometry on students' academic achievement and the permanence of their knowledge. International Journal on New Trends in Education and Their Implications. 4(1). 73-87. Tersedia di www.ijonte.org.

Utari, S., Alfiani, Feranie, S., Aviyanti, L., Sari, I. M., \& Hasanah, L. 2013. Application of learning cycle 5E model aided cmaptools-based media prototype to improve student cognitive learning outcomes. Canadian Center of Science and Education. 5(4). 69-76. Tersedia di www. ccsenet.org/apr.

Undang-undang Negara Republik Indonesia Nomor 20 tahun 2003 tentang Sistem Pendidikan Nasional.

Wibowo, A., Munir, H., \& Waslaludin. 2010. Penerapan model pembelajaran siklus belajar (learning cycle) 5E dalam meningkatkan hasil belajar siswa pada matapelajaran teknologi informasi dan komunikasi. Laporan Penelitian (tidak diterbitkan). Universitas Pendidikan Indonesia. 